\title{
Review of the Ubiquitin Role in DNA Repair and Tumorigenesis, with Emphasis in Breast Cancer Treatment; Current Data and Future Options
}

\author{
Despoina Mourtzoukou, loannis Drikos, \\ Nikolaos Goutas and Dimitris Vlachodimitropoulos \\ Additional information is available at the end of the chapter
}

http://dx.doi.org/10.5772/intechopen.72600

\begin{abstract}
Breast carcinoma remains the commonest carcinoma among women worldwide. Despite the fact that impressive progression has been achieved so far regarding pathophysiology, histopathology and treatment of this cancer, there are still undiscovered fields on molecular and therapeutic levels. The need of resolving problems such as chemoresistance, recurrence and metastasis has led in revealing key molecules in the development and progression of malignancies, including breast tumors. In this review, we will briefly describe the functions of ubiquitin and post-translational modifications (PTMs) focusing specially in DNA repair and then discuss about the implication of ubiquitin and related molecules in tumorigenesis and specifically in breast carcinoma. So far there are only few drugs approved by FDA that target the ubiquitin system. There will be an analysis regarding the current and potential anti-cancer therapeutic strategies based on targeting specific ubiquitin-related molecules.
\end{abstract}

Keywords: ubiquitin, DNA repair, deubiquitinating enzymes, breast carcinoma, target therapy

\section{Introduction}

Breast cancer is the most common carcinoma and the second cause of death among women worldwide. Incidence rates vary greatly worldwide from 19.3/100,000 women in Eastern Africa to 89.7/100,000 women in Western Europe. Although age-adjusted breast cancer mortality rates have declined by $36 \%$ from 1989 to 2012, the incidence of this carcinoma is increasing 
due to increase life expectancy and adoption of western lifestyle [1]. In US, during 2015 there were 231,840 new cases of invasive carcinoma, 60,290 new cases of in situ carcinoma and 40,290 deaths due to breast cancer, for women of all age groups [2, 3]. As of March 2017, there are more than 3.1 million women with a history of breast cancer in the US; this includes women currently being treated and women who have finished treatment [4].

This increase explains the interest for research in depth for mechanisms of tumor progression and subsequently for potential therapeutic drugs. During the last years, there has been progress in understanding the histopathology and molecular biology of breast carcinoma, but still there are many unanswered questions to be solved. The complexity of interaction between internal and external factors that lead to the evolution of breast cancer cells is evident via the variety of the clinical, morphological, histopathological and molecular characteristics of this malignancy. Currently, there are many therapeutic tools that in combination with surgery offer better survival rates and quality of life for breast carcinoma patients, including hormonotherapy, radiotherapy, chemotherapy and targeted monoclonal antibody therapy (Trastuzumab and Herceptin), depending on the tumor stage and receptors expression in each patient [4]. Despite improved treatments that have been achieved, many breast tumors are not eradicated effectively due to their resistance-intrinsic or acquired - or relapse following initial response, resulting in metastasis at later stages and subsequently to patient death. This outcome suggests that further understanding of the molecular mechanisms underlying the development of breast cancer is essential to identify new therapeutic agents and achieve better treatment. In recent years, there is an increasing interest and investigation regarding potential targets for molecular therapy. One of the most promising field concerns the different levels of ubiquitin system, however, so far there are only a handful of drugs targeting this system that have been approved by the FDA.

Mammalian cells maintain their homeostasis regarding cell cycle control through proliferation and apoptosis signals that lead to specific protein expression. Ubiquitination is one of the PTMs that are involved in a variety of complex cellular processes such as endocytosis, cell cycle progression and activating to inactivating substrates. The ubiquitin system regulates the majority of cellular activities via proteolysis and/or signal transduction - modulating proteinprotein interactions and participates in DNA damage repair. DNA repair not only has a crucial role regarding cell cycle control, proliferation and apoptosis but also in diseases, tumor progression and even metastasis of malignant neoplasms, including breast carcinoma [5].

\section{General features and functions of ubiquitin}

The genome of the organisms can be modified by epigenetic alterations, except for the DNA sequence of genes. Epigenetic modifications include DNA methylation, histone modifications (methylation, acetylation, phosphorylation, sumoylation and ubiquitination) and non-coding RNAs that lead to changes in gene expression [6]; in addition, PTMs regulate the cellular functions of most proteins - the best studied of which include phosphorylation, acetylation and ubiquitination-with constant interplay among them. All the aforementioned changes can influence both normal and disease states of an organism and are reversible. There is an interplay between PTMs on target proteins and the attachment or removal of PTMs can determine the substrate fate [7]. 
Ubiquitin is a 76-amino acid protein that is expressed in eukaryotic cells and is involved in the cell cycle regulation by proteolysis and/or signal transduction, while the majority of cellular activities are regulated with the involvement of the ubiquitin system [8].

The ligation of ubiquitin molecules to substrate proteins leads either to their degradation or can also change the substrate activity, localization and affinity to binding partners or even lead to other non-proteolytic processes [9]. Three enzymes catalyze the attachment of ubiquitin to a target protein: E1 activating enzyme, E2 conjugating enzyme and E3 ligase [8-10].

In general, the target protein is subjected to degradation with the involvement of $26 \mathrm{~S}$ proteasome, a large multi-enzyme complex $[8,10]$.

The progress in novel technologies has provided information about the structure and function of the ubiquitin and thanks to the latest mass spectrometric techniques our understanding of the complexity and diversity of the polyubiquitin chains has increased; proteins can be modified at one or more lysine $(\mathrm{K})$ residues with either a single ubiquitin molecule-mono- and multi-monoubiquitination, respectively-or with ubiquitin polymers-polyubiquitilation. Ubiquitin moieties can be conjugated through one of their lysine residues (K6, K11, K27, K29, $\mathrm{K} 33, \mathrm{~K} 48$ and $\mathrm{K} 63$ ) or the N-terminal methionine residue (M1). There can be homotypic and
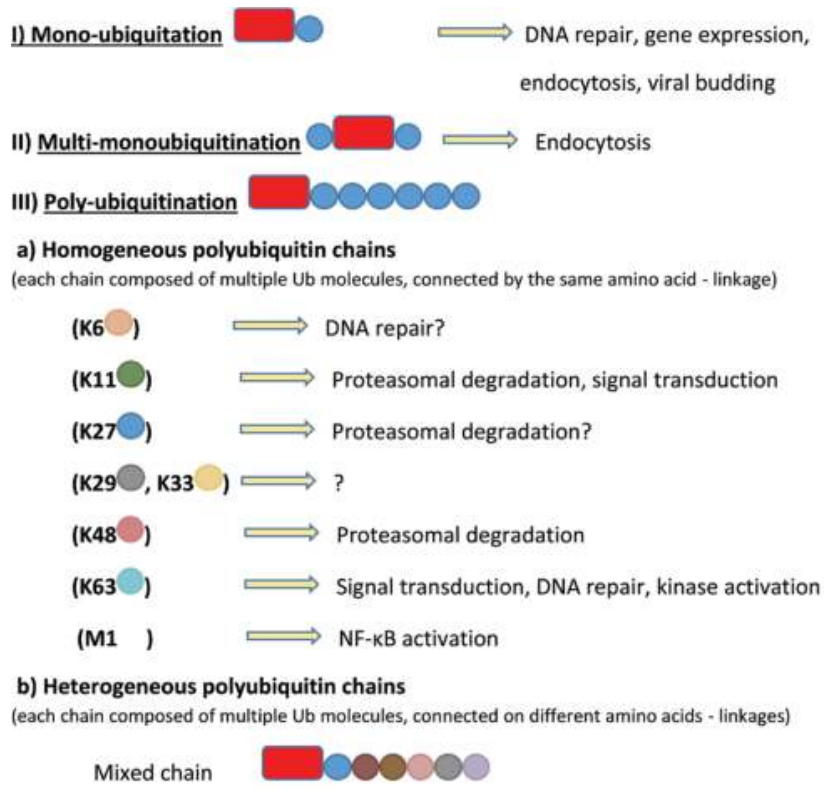

Scheme 1. Variety of Ub roles in cellular processes, regarding chains and linkage types. 
heterotypic chains, by single or mixed linkage types, respectively, and chains can be branched; also, ubiquitin molecules can be modified by PTMs (e.g. acetylation and phosphorylation) [9].

The process of ubiquitination is reversible thanks to deubiquitinating enzymes (DUBs) that count to approximately 100 in the human genome and are classified into at least 6 families (Ub-specific proteases, Ub carboxy-terminal hydrolases, ovarian tumor proteases, MachadoJoseph disease protein domain proteases, metalloenzymes and monocyte chemotactic protein-induced proteases) [11, 12]. The ubiquitin code through all these complex steps are involved not only in many biological processes such as DNA damage repair, apoptosis, cell cycle control, differentiation, but also in diseases, including carcinogenesis [12]. A lot have been achieved so far in our understanding but there are still many to be solved in the analysis of the numerous different roles of the ubiquitin code (Scheme 1, [13-15]).

\section{Ubiquitin and DNA repair}

\subsection{Ubiquitin and cell cycle control}

Ubiquitin is an essential, highly conserved protein expressed in various cells. It can be found in either free form or covalently attached to a target protein [16-18]. Ub by acting as cellular signal controls a wide range of biological processes including protein degradation, DNA repair, endocytosis, autophagy, degradation, immunity and inflammation.

$\mathrm{Ub}, \mathrm{E} 1, \mathrm{E} 2$ and E3 enzymes are successively required to target certain substrate for degradation. $\mathrm{Ub}$ is attached to specific substrates in a three-step mechanism, with distinct enzymes catalyzing each step. During first activating step, $\mathrm{Ub}$ becomes covalently conjugated to the side chain of an E1-cysteine via its carboxy-terminal (C-terminal) glycine in an ATP-dependent reaction. Activated $\mathrm{Ub}$ is transferred via E2-enzyme (ubiquitin-conjugating enzyme) at C-terminal glycine residue of $\mathrm{Ub}$ at an internal cysteine. Finally, $\mathrm{Ub}$ bound E2 interacts with an E3 Ub ligase that catalyzes $\mathrm{Ub}$ transfer from E2 to a specific target protein [19, 20].

The specificity of $\mathrm{Ub}$ signaling is accomplished due to association of the molecule with different substrates (mono- and poly-ubiquitination) [21]. The activity of protein molecules depends on the interacting region with $\mathrm{Ub}$ (UBD - ubiquitin binding domain) affecting intracellular signaling pathways [22, 23]. Monoubiquitination plays an important role in the recognition of double-strand breaks (DSBs). K63 linked chains of Ub are involved in the production of signaling processes during DNA repair [24, 25]. The ubiquitin/proteasome system (UPS) is a main regulator of protein stability and plays an important role in execution of DNA damage response (DDR). Several studies using proteasome inhibitors validated UPS as a valuable therapeutic target in cancer $[26,27]$.

Recognition of DNA damage sites by $\mathrm{Ub}$ accumulation can be detected immediately during DNA damage [28]. Ubiquitination of $\mathrm{H} 2 \mathrm{~A}, \mathrm{H} 2 \mathrm{~B}$ and $\mathrm{H} 2 \mathrm{AX}$ is crucial in order to promote destabilization of nucleosomes [29, 30]. Monoubiquitination of H2A from RNF2-BM1 cluster seems to be essential for transcriptional repression of RNA-PoI II [31]. RNF2-BM1 is also involved in monoubiquitination of H2AX at K119 and K120 (E2: UbcH5C), which initiates recruitment of the apical PI3K-related kinase ATM (ataxia telangiectasia mutated) [32, 33]. 
DNA repair process induces cell cycle arrest by non-homologous recombination (NHEJ) and phosphorylated p53. The p53 cooperates with the ATM/ATR and induces cell cycle arrest by activating apoptosis [34]. The ubiquitin selective Cdc48/p97/VCP affects Ddr protein and participates in ubiquitination and activation of degradation via proteasome [35-37]. Consequently, the interaction of ubiquitination and phosphorylation mechanism modulates the activity of many proteins such as p53.

Cell cycle procedures and DNA repair mechanisms are crucial for the genetic stability in all eukaryotic cells [38]. The NHEJ process reunites free ends of the DNA with relatively restricted homology [39]. The NHEJ process can be considered as less robust procedure according to reconnection of non-complementary ends of the chaperone activity such as DNA-PK, which remove the mismatched nucleotides [40].

The cell cycle control procedure and the reliability of the progress of NHEJ depend on the presence of NHEJ DNA repair proteins such as Ku70/80 and ligase XRCC4-IV [41, 42]. Besides NHEJ, the process of homologous recombination (HR) is also crucial for the genetic stability during predominantly $S$ and G2 cell phases demonstrated the recombination of sister chromatids or intact homologous chromosomes [43].

Protein ubiquitination plays an important role during DNA repair process, as several different molecules of the cell cycle are ubiquitinated such as 53BP1. The 53BP1 protein promotes NHEJ and HR activation and the protein interaction with BRCA1 during HR [44]. The binding of the protein to the double-strand break (DSB) region is associated with activity of the RNF8 protein. K63 acts as E3 ubiquitin ligase and catalyzes the ubiquitination of substrate proteins via RNF8 [45].

During DNA damage, RNF8 binds to the damage site interacting with MDC1 and catalyzes monoubiquitination of $\mathrm{H} 2 \mathrm{~A}$ and $\mathrm{H} 2 \mathrm{AX}$ through action of K63. The monoubiquitination of histones promotes RNF8-dependent recruitment of a second E3 ligase RNF168 at the DSB [46, 47]. The polyubiquitination of H2AX further promotes the recruitment of RNF168 which amplifies the RNF8 dependent histone ubiquitination by K63 [47, 48]. The interaction of complex RNF8/ RNF168/K63 affects the accumulation of DNA repair proteins such as BRCA1 and 53BP1.

53BP1 cannot directly bind to K63 according to absence of any relevant binding site [49]. For accumulation of 53BP1, p97 activation is necessary in order to remove L3MBTL1 protein to the DSBs sites. The p97 binds to the ubiquitinated L3MBTL1 in chromatin, affecting the binding of 53BP1 [35].

According to these, RNF8 ubiquitinates K48-dependent substrates such as JMJD [50], protein of NHEJ KU 80 [28] and polymerase DNA (PCNA), which are crucial for DNA repair procedure [51]. These proteins may be removed from chromatin by the action of the proteasome.

Polyubiquitination of PCNA may change cellular signaling of significant molecules [52]. This regulator leads to waterfall ubiquitination during the DDR. During this phase, PCNA monoor poly-ubiquitinated at K164 residue regulates DNA repair process [53, 54]. BRCA1 plays a key role through BRCA1 - BRCT domain for the cell cycle progression [55]. BRCA1 reveals E3 ubiquitin ligase activity which is vital for genomic integrity $[56,57]$.

p53 has already been identified as an important molecule for cell cycle progression. The RITA (enabler of p53 and induction of tumor apoptosis) is a small molecule that blocks p53 action [58]. 
However, it appears to be dependent by ubiquitin even if in pro-apoptotic stage has been described as p53 independent $[59,60]$. Nowadays, small molecules are designed to prevent the interaction between the p53 and MDM2, affecting in this way cell cycle control or apoptosis [61].

\subsection{The importance of ubiquitin to cellular apoptosis}

Besides the activation of DNA repair, the apoptotic response determines cellular integrity [62]. DNA damage responses depend on operation of p53 as a key factor of cell function. p53 is an important component of the mitochondrial apoptosis and plays a crucial role in the coordinated cell death by DNA damage processes.

The expression of pro- and anti-apoptotic proteins such as members of Bcl2 family is decisive for DDR signaling. The ability of apoptosis of immune cells is crucial for cellular differentiation. Almost 90\% of pre B and T cells reveal apoptosis during maturation [63].

In this process, UBE2C regulates the correct alignment of chromosomes during mitosis. Overexpression of UBE2C has been detected in many cancers including breast, colon, prostate, ovary, thymus, uterus and lung. Expression varies during the cell cycle and peaks at pro-metaphase and is reduced into anaphase [64, 65]. Suppression of expression of UBE2C contributes in tumor progression and regulates chromosome segregation during mitosis in various malignancies (cancer tissues). Overexpression of UBE2S and HIF1a is detected in various tumors such as liver, colon cancer, breast cancer and metastatic cholangiocarcinoma [66, 67].

There are approximately 600 E3 ubiquitin ligases encoded by human genome and the mechanism of ubiquitination depends on conserved catalytic domains [68, 69]. E2 and E3 ubiquitin ligase activity contribute to aberrant oncogenic signaling, metastasis and resistance to chemotherapy. STUB1 molecule demonstrated E3 ubiquitin ligase activity in cancer cells enhanced by limited expression of STIP1. The STUB1 operates as a complex with other proteins and promotes control of different regulatory molecules such as c-myc and SRC-3 through ubiquitination. The restricted expression of STUB1 regulates the signaling of NFkB and the anti-apoptotic proteins $\mathrm{Bcl} 2$ and AKT, enhancing the process of inflammation and cellular metastasis. STUB1 is E3 ubiquitin ligase which modulates the stability of the p65 subunit of NFkB in cell colon cancer lines [70, 71].

Negative regulation of expression of STUB1 affects the activity of the p65 subunit and increases VEGF, cyclin D1, c-Myc, IL-8 and MMP-2 by the action of NFkV involved in angiogenesis and cancer metastasis. According to cell lines of pancreatic cancer, STUB1 has tumor suppressor activity and regulates the stability of EGFR via proteasomal degradation mediated by tyrosine kinase receptor (RTK). The STUB1 regulates phosphorylation of EGFR at Tyr845 and Tyr1068 positions, activating signaling pathways of PI3K/AKT and Src/FAK. Downregulation of STUB1 increases oncogene signaling of EGFR and enhances action of RTK inhibitor, erlotinib, leading to apoptosis in vivo. STUB1 modulates proteasomal degradation of NFkB and the EGFR in several volumes [72-74].

The ultimate central goal of conventional cancer therapy is the effective elimination of tumors by DNA damage-induced apoptosis (DDIA) since the balance of protein abundance and functionality are decisive for DDR. Deregulation of ubiquitin-signaling pathways is intimately associated with tumorigenesis and therapy resistance [60]. 
Accumulating recent evidence conclusively identified ubiquitin signaling as a valuable target in DDR and cancer chemoresistance. The majority of these efforts focused on the regulation of p53 as one of the central determinants of DDR outcomes. Accordingly, an increasing number of specific regulators of p53 have been identified and evaluated as therapeutic target.

RITA (reactivation of p53 and induction of tumor cell apoptosis) is a small molecule that blocks p53 [58]. p53 regulates cell cycle control in different tissues including myelomas [60]. MI-63 and MI-219 molecules can block the interaction between p53 and MDM2, demonstrating that p53 mediates the disruption process of the cell cycle or apoptosis in tumor cells [61].

\subsection{The importance of ubiquitination in the evolution of cell proliferation}

Ubiquitination is a crucial post-translational modification that regulates cell cycle progression. Proteins that show E3 ubiquitin ligase activity such as SCFSKP2, SCFFBW7 and APC/C are responsible for coupling ubiquitin in different specific proteins affecting proteasome and regulation of degradation.

Many proteins with E3 ligase activity may operate either as oncoproteins or as tumor suppressors. SKP2 is an oncoprotein involved in cell cycle progression through interaction with cyclins, p27kip1 inhibitors and p21WAF/Cip1 complex [75, 76]. The identification of related E3 ligases and their substrates may be important therapeutic options for cancer treatment. Molecules such as RNF115 and BRCA2 reveal ubiquitin E3 ligase activity overexpressed in estrogen receptor (ER)-positive tumors [77].

A recent study showed that BRCA2 directly interacts with RCL [78]. The BRCA1 and BRCA2 are key molecules for the cell cycle control interacting with a large number of other factors including Rab7, UBC9 and hHR23a 14-3-3s [79, 80]. Several studies have also shown that protein p21 show ligase E3 activity interacting with SCFSkp2, CRL4Cdt2 [81], the APC/ CCdc20, MKRN1 and RNF126; BRCA2 promotes proliferation of ER-positive breast cancer cells through its interaction with p21 [82, 83].

In eukaryotic cells, CDKs activation is controlled by the availability of other cyclins and molecules, for example, p21, p27 and p57. Deregulation procedures of cyclins or CDKs determine cell cycle control and proliferation, affecting cancer progression. The process and effect of ubiquitin through regulation of proteasomal activity also plays a critical role in cell cycle control [84].

BRCA2 has E3 ubiquitin ligase activity inducing ubiquitination of p21 protein. Alterations of BRCA2 activity affect and promote proliferation of breast cancer cells. BRCA2 activity is influenced by estrogen through ER receptor activity in MCF-7 cells [78]. It has also been found that BRCA2 is expressed at high levels in ER-positive breast cancers in MCF-7 and T47D cell lines.

BRCA2 reveals $46 \%$ homology to SEQ RNF126, affecting the activity of p21 [83]. Both BRCA2 and RNF126 interact with the p21. This complex may promote ubiquitination of the protein $[82,83]$. BRCA2, RNF126 and other E3 ligases coordinately regulate the expression levels of p21. Except for p21, many other proteins interact with BRCA2 including Rab7, tetherin, UBC9, hHR23a and 14-3-3 s [82, 83]. However, BRCA2 does not appear to affect proteins degradation via ubiquitin mediation. BRCA2, by the action of an Ub ligase E3, induces proliferation of breast cancer cells via the ubiquitination of p21 and its degradation via proteasome. 


\subsection{Ubiquitin and tumor progression: Metastasis}

Overexpression of E2 molecules in tumor metastasis plays an active role in regulating cell cycle progression and inflammation processes. In cases of defective expression of E3 ubiquitin ligases, the oncogene signaling, metastasis and resistance in chemotherapy are elevated.

Downregulation of ubiquitin E3 ligase in cancer is associated with STUB1 action. STIP1 is an escort molecule which regulates the cell cycle control and promotes ubiquitination of regulators of the cell cycle such as c-Myc and SRC-3. Reduced expression and downregulation of expression of STUB1 and NFkB activates signaling of anti-apoptotic proteins, for example, Bcl2- and AKT-promoting inflammation, cell survival, cellular infiltration and metastasis [70, 71].

The reduced expression of STUB1 in colon cancer is associated with reduced degradation of the subunit p65 and increased expression of NFkB and molecules of cyclin D1, c-myc, IL-8 and MMP-2 involved in angiogenesis and procedure of metastasis [85]. In pancreatic cancer, STUB1 is a tumor suppressor and regulates the stability of EGFR via proteasomal degradation. In addition, decreased expression of STUB1 increases oncogenic signaling of EGFR in pancreatic cancer cells by limiting the response of RTK, erlotinib, affecting tumorigenesis [86].

Interaction of UBE2N/UBE2V1 affects metastasis in breast cancer cells. UBE2N shows ubiquitin ligase activity interacting with the cofactor UBE2V1 and induces ubiquitination in Lys63 residue activating NFkB during inflammation. UBE2N is overexpressed in many tumors such as breast, pancreatic, colon, prostate, ovarian and lymphoma. UBE2N is important molecule in the process of metastasis of breast cancer cells to the lung by activating TGFb mediated by TAK1 and p38 [85].

It has been shown in several studies that UBE2N E2 ubiquitin ligase (UBE2V1) is overexpressed in breast cancer cells and increases penetration and migration. Breast cancer cells are characterized by increased expression of metalloproteinase-1 (MMP1) via activation of NFkB [87, 88].

UBE2V1 inhibition via shRNAs reduced breast tumor progression and metastasis in vivo. Molecules with E3 ubiquitin ligase activity have been determined in pluripotent cancer stem cells. Pluripotent cancer stem cells are characterized by overexpression of the embryonic stem cell markers SOX2 (SRY-2), Oct4 (Octamer-4) and Nanog. These transcription factors are key regulators of pluripotency and of the inhibition of cellular differentiation. Specific indicators in the surface of cancer cells CD133 and CD44 are associated with increased resistance to chemotherapy. E3 ligases control cell differentiation by regulation of expression of these specific proteins in different cancer types [89].

\section{Ubiquitin-related molecules and breast cancer; target therapy}

\section{1. p53/MDM2}

In about $50 \%$ of human malignancies there is mutation of TP53, making this "genome guardian" the most frequently mutated gene in cancer [90,91]. In addition, for most cancers lacking mutation, the wild-type p53 is inactivated by interaction with cellular (MDM2/MDM4) or viral proteins that lead to its degradation. For these reasons, there is a great interest regarding targeting these molecules for the cancer treatment and during the last years several compounds have 
become available that can restore wild-type properties of p53 for TP53-mutated malignancies or prevent the binding of MDM2/MDM4 to wild-type p53, thereby blocking its degradation in a variety of malignancies; the disparity provides distinct therapeutic opportunities for targeting cancers with p53 wild-type than those with p53 mutant cancers. Several preclinical studies have demonstrated that reconfiguration of mutant, to its normal, active WT p53 conformation, restores apoptosis and promotes tumor regression (88). Although the overall frequency of p53 mutation in breast cancer is approximately $20-30 \%$ (70-80\% are TP53 wild-type), certain types of it are associated with higher frequencies, for example, in carriers of germline BRCA1 and BRCA2 mutations, strikingly, in typical medullary breast carcinomas, p53 mutation occurs in 100\% of cases [92, 93]. In addition, TP53 mutation distribution is highly linked to molecular breast tumor subtypes found in $26 \%$ of luminal tumors (17\% of luminal A and $41 \%$ of luminal B), in 50\% of HER2-amplified tumors, in $69 \%$ of molecular apocrine breast carcinomas and in $88 \%$ of basal-like carcinomas [93].

In general, patients carrying a TP53 missense mutation, leading to expression of a mutant p53 protein in the germline, have a significantly earlier cancer onset than patients with mutations in TP53 that result in loss of p53 protein expression. Mutant p53 has been shown to play a role in many different cellular processes, for example, proliferation, invasion, increased migration, genomic instability, cell survival, angiogenesis, EMT, stem cell dedifferentiation and drug resistance. The tumor suppressor role of wild-type p53 is undoubtable, but studies showed that mutated p53 can result in both loss of wild-type activity and gain of a novel functions, promoting tumorigenesis and a more aggressive tumor profile [94]. The strategies that are currently being explored to target mutant p53 include small molecule compounds that specifically restore wild-type conformation and transcriptional activity of mutant p53, induce depletion of mutant p53, inhibit the downstream pathways of oncogenic mutant p53 and induce synthetic lethality to mutant p53 $[95,96]$. The fact that most mutant p53s are expressed at very high levels in cancer cells, leading to their immunohistochemical detection, makes these proteins very attractive therapeutic targets.

\subsubsection{Hsp90 inhibitors: geldanamycin, 17-AAG and ganetespib}

Blocking the function of heat shock protein 90 (Hsp90) leads to depletion of several oncogenic proteins such as ErbB2 and mutant p53, because Hsp90 contributes to the accumulation of mutant p53 by inactivating p53 ubiquitin ligases, MDM2 and CHIP [95]. Geldanamycin is one of the most potent and effective hsp90 alpha inhibitor and is used to target breast cancer; however, it failed to move into the clinics due to the toxicity associated with its solubility. Geldanamycin was modified chemically to develop 17-AAG and later 17-DMAG, which have higher solubility and lesser toxicity [97]. Nonetheless, in order to achieve better efficacy against breast cancer, a more potent, soluble and least toxic analogues need to be developed such as an analogue and geldanamycin-based polymeric magnetite nanocomposite; the latter plays a vital role in efficacious therapy, showing selective cell kill of cancerous breast cells, while vanquishing normal cells and hepatic toxicity [98]. Another Hsp90 inhibitor, ganestespib, has proved to have little effect on wild-type p53 levels and induces mutant p53 depletion with increased apoptosis in tumors in vivo in both p53 $3^{\mathrm{R} 248}$ Hupki (human p53 knock-in) and $\mathrm{p} 53^{\mathrm{R} 172 \mathrm{H}}$ knock-in mouse models. Ganetespib is under evaluation in clinical trials, supported by preclinical evidence of its potent anti-tumor activity in different breast cancer subtypes; a phase II trial of single agent ganetespib was conducted in patients with unselected 
metastatic breast cancer. The clinical activity was notable in patients with trastuzumab-refractory HER2+ and triple negative breast cancer. In addition there was evidence of tumor shrinkage, specifically in patients with lung metastases. In that trial ganetespib was well tolerated, thus responses in more targeted populations harboring specific HSP90-dependent oncoproteins justify its further study [99].

\subsubsection{Histone deacetylase inhibitors (vorinostat/SAHA, romidepsin/depsipeptide, belinostat)}

Histone deacetylases (HDACs) are a group of enzymes that remove acetyl groups from histones and regulate expression of tumor suppressor genes such as p53. HDAC inhibitors (HDACi) have the potential to disrupt multiple signaling pathways to inhibit tumor growth and induce apoptosis. HDAC inhibitors are differentiated by their structure and further characterized into different subgroups [100]. Specifically, suberoylanilide hydroxamic acid (SAHA, also known as vorinostat), a FDA-approved HDACi that inhibits class I, II and IV HDACs, induces degradation of mutant p53 by inhibiting HDAC6 activity, an essential positive regulator of Hsp90 and subsequent disruption of the HDAC6/Hsp90/mutant p53 complex, leading to mutant p53 ubiquitination by MDM2 and CHIP. SAHA shows higher cytotoxic effects on cancer cells carrying mutant p53 than those having wild type or null for p53. SAHA also sensitizes cancer cells to a topoisomerase inhibitor camptothecin in a mutant p53-dependent manner. Currently, all three drugs approved by FDA (vorinostat (SAHA), romidepsin/ depsipeptide (Istodax)) and belinostat (Beleodaq) are being further evaluated for other than hematological malignancies and for solid tumors, either as a single agent or in combination with other drugs. Specifically, investigation of romidepsin for the treatment of inflammatory breast cancer revealed that it potentially induced destruction of IBC tumor emboli and lymphatic vascular architecture. Also, a combination of depsipeptide and gemcitabine was tested in patients with advanced solid tumors including pancreatic, breast, NSCLC and ovarian and the study identified a dose level of $12 \mathrm{mg} / \mathrm{m}^{2}$ romidepsin and $88 \mathrm{mg} / \mathrm{m}^{2}$ gemcitabine for phase II trial [101]. Clinical trials studying the combination of chemotherapy or hormone therapy and HDAC inhibitors show promising efficacy. [100].

\subsubsection{Beclin1}

Autophagy is an important intracellular catabolic mechanism that mediates the degradation of cytoplasmic proteins and organelles. We report a potent small molecule inhibitor of autophagy named "spautin-1" for specific and potent autophagy inhibitor-1. Spautin-1 promotes the degradation of Vps34 PI3 kinase complexes by inhibiting two ubiquitin-specific peptidases, USP10 and USP13 that target the Beclin1 subunit of Vps34 complexes. Beclin1 is a tumor suppressor and frequently monoallelically lost in human cancers. Interestingly, Beclin1 also controls the protein stabilities of USP10 and USP13 by regulating their deubiquitinating activities. Since USP10 mediates the deubiquitination of p53, regulating deubiquitination activity of USP10 and USP13 by Beclin1 provides a mechanism for Beclin1 to control the levels of p53 [102]. One study provided a molecular mechanism involving protein deubiquitination that connects two important tumor suppressors, p53 and Beclin1, and a potent small molecule inhibitor of autophagy as a possible lead compound for developing anti-cancer drugs. Actually, since Beclin 1 is expressed in breast cancer cells, it could be a unique effective 
drug target for the prevention and treatment of breast cancer. However, the expression of Beclin 1 varies according to cancer molecular subtypes, and Beclin 1 is involved in both breast cancer suppression and tumor progression; therefore, the decision of using a Beclin 1 inducer or inhibitor should be made based on breast cancer stage and subtype [103].

\subsubsection{Nutlin-3a}

In 2004, a small molecule antagonist of Mdm2 was discovered, known as Nutlin-3a or Nutlin. The discovery of nutlin-3a, the first in a class of small molecule MDM2 inhibitors that binds to MDM2, preventing its association with and degradation of p53, has led to an extensive list of related compounds. Preclinical modeling with nutlin-3a showed improved anti-cancer activity in combination with cytotoxic- and molecular-targeted therapies, in many tumor types; the high rate of MDM2 overexpression in ER-positive breast cancer, and the ability of MDM2 inhibitors to ubiquitinate steroid hormone receptors, has led to the evaluation of this class of drugs in combination with endocrine therapies [104]. It has also been shown that p53 activation with nutlin in combination with fulvestrant, a selective ER degrader, leads to a greater degree of apoptosis in vitro. However, the subsequent toxicity of the combination partner plays critical role for the success of such an approach clinically.

Also, there has been shown the potential of Nutlin-3 or similar drugs as treatment options to overcome chemoresistance due to cancer stem cells (CSCs) [105]. In a recent study, patientderived xenografts were used, as a clinically relevant model of numb-deficient breast cancers; the unlimited self-renewal and high tumorigenic/metastatic potential of cancer stem cells in numb-deficient carcinomas could be selectively reverted by re-expression of the tumor suppressor numb, or pharmacological restoration of p53 function with the Nutlin-3. Targeting the numb/p53 dysfunction selectively interferes with the CSC compartment of numb-deficient BCs, with only modest effects at the level of the bulk tumor population. The combined use of Nutlin-3 with standard chemotherapy (paclitaxel), increases the response to therapy of numb-deficient breast carcinomas and prevents tumor relapse after therapy discontinuation [106].

\subsubsection{RING finger protein 31 inhibitors}

The atypical E3 ubiquitin ligase RNF31 (other names HOIP and ZIBRA) is highly expressed in breast cancer, decreasing p53 stability, whereas depletion of RNF31 in breast cancer cells causes cell cycle arrest and cisplatin-induced apoptosis in a p53-dependent manner. Furthermore, RNF31 is associated with the p53/MDM2 complex and facilitates p53 polyubiquitination and thus its degradation, suggesting that RNF31 regulates cell death. As p53 wild type tends to appear in ER $\alpha$-positive breast cancers (Luminal A and B), there is still little known about RNF31 in HER2 type or triple negative breast cancers. Analysis of publically available clinical data sets displayed a negative correlation between RNF31 and p53 target genes, including IGFBP3 and BTG1, consistent with the fact that RNF31 regulates p53 function in vivo as well, findings suggesting RNF31 as a potential therapeutic target to restore p53 function in breast cancer [107, 108]. A lot need to be investigated by future studies on the development of drug targets (RNF31 inhibitors) and their clinical application. 


\subsection{CDKs - CDIs}

Cell cycle regulation has been identified as an attractive target for targeted drug therapy of cancer. Several compounds of CDK inhibitors entered preclinical and early clinical trials including first- and second-generation agents that are more specific to certain CDKs.

\subsubsection{Palbociclib and related molecules}

The results with broadly acting CDK inhibitors (first-generation inhibitors such as flavopiridol) so far were largely disappointing. The second-generation compounds have shown more potent activity against their targets and a more favorable safety profile. Recent preclinical and clinical studies using a novel (oral) reversible CDK4/6 inhibitor, palbociclib, have shown the role of CDK4/6 as a potential target in estrogen receptor-positive $(\mathrm{ER}+)$ breast carcinoma. Specifically palbociclib (PD0332991) has recently received accelerated Food and Drug Administration approval for the treatment of hormone receptor-positive ( $\mathrm{HR}+)$ metastatic breast cancer in combination with letrozole, while further data suggest improved outcome when combined with fulvestrant (hormonotherapy). In addition to palbociclib, two other small molecule CDK4/6 inhibitors are currently in clinical development, ribociclib (LEE011) and abemaciclib (LY2835219); actually the FDA has approved the CDK 4/6 inhibitor ribociclib (Kisqali) for use in combination with an aromatase inhibitor for the frontline treatment of postmenopausal women with HR+, HER2-negative advanced breast cancer $[109,110]$. Finally, treatment with the CDK4/6 inhibitor abemaciclib has been approved by FDA in 2017, for HR + and HER2 - advanced or metastatic breast carcinoma [111].

\subsection{SCF complex - SKP2/p27}

\subsubsection{SKP2 inhibitors}

It has been proved that Skp2 is frequently overexpressed in a variety of human cancers including breast carcinoma; actually both Skp2 mRNA and protein display elevated levels in breast cancer cell lines and primary breast tumors. Therefore, inhibition of Skp2 may be a novel strategy for the prevention and/or treatment of this malignancy. Specific drugs that inactivate Skp2 in breast cancer are unavailable so far, although there is renewed interest in developing Skp2 inhibitors for breast cancer treatment.

It is noteworthy that several natural compounds have been found to downregulate Skp2 expression in human cancers-including breast cancer-such as curcumin, lycopene and quercetin. All-trans retinoic acid (ATRA) promoted the ubiquitination of Skp2 in breast cancer cell lines, leading to cell cycle arrest. Gallic acid markedly reduces cell growth of human breast cancer cells and induces cell cycle arrest by inhibiting Skp2, attenuating Skp2-p27 association and reducing p27 ubiquitination. Moreover, Huang et al. (2008) reported that epigallocatechin-3-gallate (EGCG), the main constituent of green tea, inhibits human breast cancer cell growth via downregulation of Skp2 expression and accumulation of p27 among others. Both tamoxifen and paclitaxel significantly and synergistically enhanced cell growth inhibition by EGCG mediated through the downregulation of Skp2 expression in breast cancer cells [112].

In addition, siRNA gene silencing-an important gene function analysis method widely used in molecular studies - could be useful tool in inhibiting Skp2 activity. At the cell level, 
siRNA interference technology is characterized by a shorter action cycle and fewer side effects, and can silence multiple genes specifically with minimized side effects. In a recent study, two pairs of SKP2-specific siRNA, siRNA1 and siRNA2, were designed and synthesized and detected the endogenous SKP2 expression inhibitory effect in breast cancer cells MDA-MB-231. Western blotting showed that SKP2-specific siRNA1 can effectively inhibit endogenous SKP2 expression in these cells. Moreover, SKP2 silence significantly reduced breast cancer cell MDA-MB-231 proliferation. This study could be the experimental basis for further investigation and potential clinical application [113].

\subsection{Histone ubiquitination}

Monoubiquitination is one of the largest histone PTMs, alongside smaller and better studied modifications such as methylation, acetylation and phosphorylation. Monoubiquitination of histone $\mathrm{H} 2 \mathrm{~B}$ at lysine 120 (H2Bub1) has key roles in transcription, the DNA damage response and stem cell differentiation. Global levels of monoubiquinated histone H2B (H2Bub1) are low to absent in advanced cancers including breast, colorectal, lung and parathyroid, marking H2Bub1 and the enzymes that regulate it as key molecules in new therapeutic strategies for the treatment of cancer. More specifically, H2Bub1 levels were found to be significantly reduced in malignant and metastatic breast cancer cells, proving its tumor suppressor role [114].

\subsubsection{USP44 inhibitors}

USP44 is a subunit of the N-CoR complex and deubiquitinates $\mathrm{H} 2 \mathrm{~B}$ in vitro and in vivo. ChIP experiments confirmed that USP44 recruitment reduces $\mathrm{H} 2 \mathrm{Bub} 1$ levels at N-CoR target loci; USP44 high expression correlates with reduced levels of H2Bub1 in the breast cancer cell line MDA-MB-231 and is required for efficient invasiveness of triple negative breast cancer cells - highly expressed in aggressive breast cancer MDA-MB-231 cells, leading to low global $\mathrm{H} 2 \mathrm{Bub} 1$ levels and contributing to the invasiveness of these cells. On the contrary, depletion of USP44 impairs the invasiveness of MDA-MB-231 cells in vitro and causes an increase of global H2Bub1 levels [115]. In recent years, studies are looking for negative regulators of DUBs such as USP44 and USP22, to be used as therapeutic agents for malignancies, including mammary carcinoma, but there are still a lot to be discovered in this field for an anti-cancer regiment to be suggested [116].

\subsection{Estrogen receptor}

On a molecular basis, for example, gene expression profile, the breast carcinomas are classified into five major subtypes: luminal A and B, HER2-enriched, triple negative (basal-like and non-basal-like). Each of these tumors has different risk factors, response to treatment and disease progression/preferential metastasis sites. In addition, the etiology, pathogenesis and prognosis of breast cancer are significantly influenced by intrinsic molecular breast cancer subtypes across the different ethnicities globally [117].

More than two-thirds of the breast carcinomas (approximately 75\%) are of luminal subtype and initially responsive to anti-estrogens such as tamoxifen. Anti-estrogen resistance is of two 
types, de novo and acquired, and is likely to develop over time. The absence of both ER $\alpha$ and PR expression represents the prevailing mechanism of de novo resistance. The acquired resistance is defined by loss of anti-estrogen responsiveness by initially responsive tumors [117]. About $50-60 \%$ of ER-positive tumors respond to the first-line endocrine therapy, while about $40 \%$ of ER-positive tumors show resistance; the latter correlated with loss of ER expression, changes in ER $\alpha$ post-translational modifications, loss of ER-dependent growth, and activation of crosstalking pathways. About one-third of patients treated with tamoxifen for 5 years will have recurrent disease within 15 years [118]. It has been proved that approximately $25 \%$ of ER+/PR+, $66 \%$ of ER+/PR- and 55\% of ER-/PR+ breast carcinomas do not respond to anti-estrogens. Several studies suggest that loss of ER $\alpha$ can be due to long-term activation of growth factor signaling pathways; approximately $30 \%$ of the patients show loss of ER $\alpha$ where EGFR/Her-2 activity is elevated. Accumulating evidence suggests that several mechanisms act at cellular/molecular levels and are likely to be responsible for the endocrine resistance, comprising a major challenge today in treating significant percentage of breast cancers by hormone therapy [118].

One contributing factor for the phenomenon of endocrine resistance is the ER $\alpha$-specific ubiquitin ligases. Re-expression of ER $\alpha$ in ER-negative breast cancer cells can restore sensitivity to tamoxifen; restoring the ER $\alpha$ expression by inhibiting ER $\alpha$-specific ubiquitin ligases provides potential novel strategies for restoring tamoxifen sensitivity and thus potential therapeutic drugs. Small molecule inhibitors specific to these ubiquitin ligases may overcome tamoxifen resistance in breast cancers. In particular, whether ER negativity is a cause or a consequence of the disease progression is a million dollar question in this field, but the current understanding of this phenomenon is still at premature stage [118].

\subsubsection{GSK3 inhibitors}

Glycogen synthase kinase-3 (GSK-3) protects ER $\alpha$ from proteasomal degradation and plays a crucial role in ER $\alpha$ protein stabilization and turnover and GSK-3 may be involved in ER $\alpha$ mediated transcriptional activation without ER $\alpha$ degradation. Silencing of GSK-3 results in a reduction of ER $\alpha$ levels in breast cancer cells due to increased proteasomal degradation, so its inhibitors could consist an emerging therapeutic target in the treatment of human breast cancer [119]. In a recent study, the pharmacological inhibition of GSK-3 by two novel small molecules, 9-ING-41 and 9-ING-87, reduced the viability of breast cancer cells; in addition, treatment with 9-ING-41 enhanced the anti-tumor effect of irinotecan (CPT-11) against breast cancer cells in vitro. The same study established two patient-derived xenograft tumor models - from metastatic pleural effusions obtained from patients with chemo-refractory breast cancer-and demonstrated that 9-ING-41 also potentiated the effect of the chemotherapeutic drug CPT-11 in vivo, leading to regression of established tumors in mice. These results make GSK-3 inhibitor 9-ING-41 a promising candidate targeted agent for metastatic breast cancer therapy [120].

\subsubsection{RNF31 inhibitors}

The atypical E3 ubiquitin ligase RNF31 has an oncogenic role in breast cancer growth through facilitating ER $\alpha$ signaling and suppressing P53 signaling, although its ultimate role is not thoroughly studied yet. Modulation of ER $\alpha$ levels is one feasible approach to inhibit estrogen signaling and subsequently cellular proliferation and possible therapeutic inhibitors targeting 
RNF31 could constitute a valuable drug for breast cancers. The development of RNF31 inhibitors is ongoing, for example, targeting its function on RBR domain [108].

\subsection{BRCA1}

The breast and ovarian cancer susceptibility gene BRCA1 is implicated not only in familial breast cancers but also in sporadic breast cancers. Approximately $15 \%$ of sporadic breast cancers belong to the basal-like subtype that expresses basal/myoepithelial cell markers, but do not express estrogen receptor, progesterone receptor or HER2 and is associated with poor prognosis. Furthermore, the majority of hereditary breast cancers with BRCA1 mutations display a basal-like phenotype, thus implying the importance of BRCA1 not only in familial breast cancers but also in sporadic cancers. BRCA1 is a protein that coordinates a diverse range of cellular pathways to maintain genomic stability and participates in multiple cellular supercomplexes, in most of which it exists as a RING heterodimer with BARD1 to provide ubiquitin E3 ligase activity that is required for a tumor suppressor function. Reduced expression of BRCA1, due to mutations or epigenetic inactivation, leads to increased risk of breast cancer development. Although BRCA1 is present in all cells, it is still not clear why mutations in the BRCA1 gene predispose to breast and ovarian, but not to other types of cancer [121].

\subsubsection{PARP inhibitors}

Poly-ADP-ribose polymerases (PARP) are enzymes that are involved in DNA damage repair and their inhibition is a promising strategy for targeting cancers with defective DNA damage repair, including BRCA1 and BRCA2 mutation-associated breast and ovarian cancers. Several PARP inhibitors are currently in clinical trials in the adjuvant, neoadjuvant and metastatic settings for the treatment of BRCA-mutated breast carcinoma (phase 2-3) such as Olaparib (AZD2281), Veliparib (ABT-888) and Talazoparib (BMN-673), as single agents or in combination schemes with chemotherapy and the results are very promising. Also, PARP inhibitor activity could be applied to breast cancers without BRCA1/2 mutations and several preclinical experiments support this possibility [122]. FDA has approved Lynparza (olaparib) to treat ovarian cancers in women who carry mutations in BRCA1 or BRCA2, and who have received chemotherapy treatments, but PARP inhibitors are not currently FDA approved for treating breast cancer; results from phase 3 using Lynparza has been promising. Nevertheless, more investigation needs to be done in order to have more data regarding possible long-term side effects $[122,123]$.

\subsection{ErbB2/HER2/neu}

Her-2/neu overexpression (gene amplification) is observed in about $20-30 \%$ of breast cancer patients and is directly linked to deregulated activation of intracellular mitogenic signaling, and thus leads to aggressive tumor behavior and resistance to cancer chemotherapy. HER-2 gene amplification in breast cancer has been associated with tumor invasiveness, accelerated angiogenesis, reduced apoptosis, and more progressive regional and distant metastases. So, carcinomas that present with a higher-than-average/'positive'HER-2 status will almost certainly be more aggressive [124]. 
The first approved monoclonal antibody treatment (immune targeted therapy) for breast cancer was trastuzumab (Herceptin), which results in significant improvement in patient survival when used in combination with chemotherapy in patients with (metastatic) Her2/neu-positive carcinoma, both before and after surgery. Specifically trastuzumab blocks HER2 receptors from receiving growth signals so it inhibits signaling of MAPK and PI3K pathways, promotes cell cycle arrest and induces apoptosis. Herceptin can also help fight breast cancer by alerting the immune system to destroy cancer cells onto which it is attached and by mediating the internalization and degradation of the Her-2/neu receptor and consequently diminishing its intracellular signaling [125].

Treatments that specifically target HER2 are very effective and the prognosis for HER2positive breast cancer is actually quite good. Other treatments that target HER2/neu receptor include Lapatinib (Tykerb), Pertuzumab (Perjeta) and/or Ado-trastuzumab emtansine (Kadcyla). Nevertheless, the primary or acquired resistance as well as the side effect toxicity of trastuzumab, for example, cardiac dysfunction have led to the investigation of other molecules that could downregulate HER2/neu. Several new medications are being developed are under clinical trials [126].

\subsubsection{Quercetin}

The natural product quercetin $\left(3,5,7,3^{\prime}, 4^{\prime}\right.$-pentahydroxyflavone) is orally bioavailable and is a flavonoid found in many fruits and vegetables. Previous research has shown that quercetin has anti-tumor, anti-inflammatory, anti-allergic and anti-viral activities and has been shown to be protective against breast cancer in animal model. A recent study showed that quercetin decreased the level of Her-2/neu protein in time- and dose-dependent manner and also inhibited the downstream survival PI3K-Akt signaling pathway in Her-2/neu-overexpressing breast cancer SK-Br3 cells. In addition, this product-induced polyubiquitination of Her-2/ neu. The carboxyl terminus of Hsc70-interacting protein (CHIP), a chaperone-dependent E3 ubiquitin ligase, was found to play a crucial role in the quercetin-induced ubiquitination of Her-2/neu. Inhibition of tyrosine kinase activity of Her-2/neu by quercetin could indicate a lateration in the Her-2/neu structure which promotes CHIP recruitments and downregulation of Her-2/neu. So this agent could be one more promising drug to treat Her-2/neu-overexpressing cancers [127].

\subsubsection{Afatinib}

The novel next-generation tyrosine kinase inhibitors (TKIs), afatinib and neratinib, were designed to overcome the resistance by targeting multiple HER family members and irreversibly binding the targets. Despite the encouraging results of the afatinib monotherapies, multicenter international trials are still ongoing for their evaluation. Neratinib has been shown to be an effective treatment in the metastatic, neoadjuvant and adjuvant setting, both as a single agent or in combination with cytotoxic agents [128]. Recently, in July 2017, the US FDA approved neratinib for the extended adjuvant treatment of early stage HER2- overexpressed/ amplified breast cancer, to follow adjuvant trastuzumab-based therapy [111]. 


\subsection{TRAIL receptors}

\subsection{1. rhTRAIL}

Drugs based on tumor necrosis factor-related apoptosis-inducing ligand (TRAIL) is anticipated to be one of the most effective cancer treatments, however, resistance to TRAIL therapy remains a challenge and TRAIL combinations have been experimented with for over 10 years to induce synergism or sensitize resistant cancer cells. TRAIL is characterized by its ability to induce apoptosis in tumor cells but not in normal cells, thus qualifying as a potential drug specific for different types of cancer, including breast, bladder, lung and liver; the development of recombinant human TRAIL (rhTRAIL) as a promising therapy for different types of human cancer. However, a majority of breast cancer cell lines exhibit resistance to TRAIL treatment due to upregulation of pro-apoptotic proteins, downregulation of anti-apoptotic proteins and/or upregulation of death receptors 4 and 5. To overcome TRAIL resistance, a cotreatment option has been studied using the natural compound Quercetin [129]. One recent studies findings suggest that the co-treatment of Quercetin and rhTRAIL has the potential to be an anti-breast cancer therapeutic strategy, by enhancing pro-apoptotic and anti-proliferative effects in hormone dependent and triple negative breast cancer cells [130].

\subsection{NEDD4}

NEDD4 (neural precursor cell expressed, developmentally downregulated 4) is an E3 ubiquitin protein ligase that has been found to target numerous substrates for its biological functions and plays a pivotal role in the development and progression of human cancers; it is observed that NEDD4 expression was increased in breast cancer [131]. Additionally, it acts as an E3 ligase of PTEN-a tumor suppressor gene - catalyzing poly-ubiquitination of PTEN protein in cells and leading to its proteolysis. It has been reported to negatively regulate PTEN protein levels in carcinomas of the prostate, lung and bladder, but recent studies showed either no association or a positive correlation at the protein and transcript levels, regarding NEDD4's effect on PTEN in the breast cancer; this suggests that NEDD4 is not responsible for the frequent downregulation of PTEN protein in human breast carcinoma [132]. In general, NEDD4 could be a legitimate target for designing new drugs against human malignancies, although surprisingly, NEDD4 inhibitors have not been discovered so far. More investigation on this pathway could lead to the development of this E3 ubiquitin ligase inhibitors such as beta-TRCP that could contribute to the decrease of abundant NEDD4 oncoprotein levels by its destruction [133].

\subsection{DUBs}

Ubiquitination is reversible, like most regulatory cellular processes, and the enzymes that reverse protein ubiquitination are collectively known as deubiquitinases (DUBs). The mammalian genome encodes around 100 DUBs that are categorized into five classes, four of which are thiol proteases including ubiquitin C-terminal hydrolases (UCHs), ubiquitin-specific proteases (USPs), ovarian tumor domain DUBs and machado Joseph domain DUBs. The fifth class comprises JAB1/MPN metalloenzyme, which functions as a zinc finger metalloprotease [134]. 


\subsubsection{USP inhibitors}

Generally, a number of regulate processes associated with cell proliferation and apoptosis, and as such represent candidate targets for cancer therapeutics. The majority of DUBs is cysteine proteases and is likely to be more "druggable" than E3 ligases. Ubiquitin-specific proteases (USPs) are one class of DUBs implicated in breast cancer by transforming growth factor beta (TGF$\beta$ ) signaling; the latter has a well-documented role in mediating epithelial-to-mesenchymal transition (EMT), tumor progression and metastasis in breast cancer. Specifically, the deubiquitinases USP4, USP9X, USP9Y, USP10, USP11, USP15, USP25 and USP32, but also DUB3 are upregulated/overexpressed in human breast cancer [134].

Several inhibitors have been developed against USPs such as HBX 41,108, b-AP15 and pimozide. WP1130 is a partially selective DUB inhibitor that induces apoptosis in cells through rapid accumulation of poly-ubiquitinated proteins that targets USP5, USP9X and USP14, among others. USP9X inhibition by WP1130 in tumorigenic human breast cancer cell lines inhibits their growth and USP9X knockdown in all triple negative breast cancer cell lines caused apoptosis induction, so WP1130 and its derivatives could be a significant therapeutic agents in the treatment of breast cancer [134]. Moreover, the specific inhibitor WP1130 binds to DUB3 and inhibits the DUB3-mediating Snail1 stabilization in vitro and in vivo, as it blocked tumor cell migration, invasion and suppressed CSC-like properties, providing a proof for therapeutic development of small molecules to inhibit the activity of DUB3 in metastatic breast cancer. These data strengthen the view that DUB3 is an ideal candidate for the development of inhibitors for cancer treatment based on its dual role in regulating cell growth and metastasis [135].

b-AP15, an inhibitor for both UCH37 and USP14, was able to accumulate ubiquitinated substrates and had excellent efficacy in different in vivo solid tumor models, as well as an acute myeloid leukemia model. On the contrary, a more selective USP14 inhibitor, IU1, had an opposite effect by enhancing degradation of target proteins, leading to a dose-dependent reduction in overexpressed proteins including Tau, showing that selective inhibition of different proteasomal DUBs may have different outcomes; nevertheless inhibition of proteasomal DUBs is worthy of investigation as a potential anti-cancer therapy [136].

\subsection{Antiestrogens (Tamoxifen, Raloxifene, Fulvestrant, Letrozole)}

Antiestrogens are classified as selective estrogen receptor modulators (SERMs), for example, tamoxifen and raloxifene-that have antagonist activity in breast and partial agonist activity in uterus and bones - and as pure antiestrogens, for example, fulvestrant; the latter accelerate ERa proteasomal degradation so they represent selective estrogen receptor downregulators (SERDs). Tamoxifen is the first clinically approved antiestrogen and remains the standard adjuvant treatment for all stages of primary breast carcinoma [137]. It has been shown that ubiquitin ligase c-Cbl is involved (enhances) in tamoxifen-induced apoptosis of MCF-7 cells [138]. Nevertheless, significant number of these patients develop resistance to tamoxifen, which in addition shows negative side effects, such as thromboembolic events and endometrial cancer. Raloxifene has $76 \%$ of effectiveness of tamoxifen at reducing incidence of invasive breast cancer with less incidence of endometrial cancer. Fulvestrant acts via different molecular 
mechanism consisting in increased ERa turnover through the ubiquitin - proteasome pathway in ERa+ breast cancer cells [137]. Finally, it has been shown that inhibition of ubiquitin conjugating enzyme UBE2C reduces proliferation and sensitizes breast cancer cells to letrozole - an aromatase inhibitor-tamoxifen etc. [139]. All the above-mentioned antiestrogen drugs are FDA-approved and have been used in HR+ (advanced/metastatic) breast carcinomas, including for reducing cancer risk (tamoxifen, raloxifene) [111].

\section{Conclusion}

Ubiquitination involves the attachment of ubiquitin to numerous target proteins leading to regulation of their half-life, localization, activity and conformation. Recent years' analysis suggests that ubiquitin plays a very important role in several signaling and cell regulatory events in malignancies, including breast cancer, which remain the commonest carcinoma and second cause of death among women worldwide. Targeting molecules of the ubiquitination system is very promising for the treatment of breast cancer, as well as for other neoplasms. Although many potential targets that belong to this category are under trials, only few have already taken FDA approval and are used as therapeutic drugs so far such as ribociclib (Kisqali) and palbociclib (PD-0332991). Suberoylanilide hydroxamic acid (SAHA) also known as vorinostat, romidepsin (Istodax) and depsipeptide are HDAC inhibitors that are being used among others in clinical trials for treating breast malignancies, but also other molecules such as ganetespib and olaparib; yet, more targets are studied as possible treatment candidates, for example, nutlin-3 and quercetin (Table 1). In spite of the fact that drug targets belonging to the spectrum of ubiquitin system are very promising, a lot need to be done by future studies on their development and clinical application, either as monotherapy or as combination therapy for breast cancer.

\begin{tabular}{|c|c|c|c|c|}
\hline \multirow{2}{*}{$\begin{array}{l}\text { Drug-related } \\
\text { molecule }\end{array}$} & \multicolumn{4}{|c|}{ Current phase } \\
\hline & $\begin{array}{l}\text { Molecule } \\
\text { selection/design } \\
\text { production }\end{array}$ & $\begin{array}{l}\text { Preclinical modeling- } \\
\text { in vitro/in vivo (cell } \\
\text { lines, xenografts) }\end{array}$ & Clinical trials & FDA approved \\
\hline \multirow[t]{2}{*}{ P53/MDM2 } & $\begin{array}{l}\text { Beclin } 1 \text { inducer } \\
\text { or inhibitor }\end{array}$ & Nutlin-3 & $\begin{array}{l}\text { Hsp90 Inhibitors } \\
\text { (Geldanamycin, } \\
\text { 17-AAG, Ganetespib) }\end{array}$ & \\
\hline & $\begin{array}{l}\text { RING finger } \\
\text { protein } 31 \\
\text { inhibitors } \\
\text { (RNF31i) }\end{array}$ & & $\begin{array}{l}\text { Histone Deacetylase } \\
\text { Inhibitors (Vorinostat/ } \\
\text { SAHA, Romidepsin/ } \\
\text { Depsipeptide, } \\
\text { Belinostat) }\end{array}$ & \\
\hline
\end{tabular}

CDKs-CDIs

SCF complex $-\mathrm{SKP} 2 / \mathrm{p} 27$

Histone H2B
Curcumin, lycopene, pentagalloylglucose, quercetin, ATRA, garlic acid, EGCG, SKP2 siRNA

USP44 inhibitors
CDK4/6 inhibitors (Palbociclib, Ribociclib, Abemaciclib) 


\begin{tabular}{|c|c|c|c|c|}
\hline \multirow{2}{*}{$\begin{array}{l}\text { Drug-related } \\
\text { molecule }\end{array}$} & \multicolumn{4}{|c|}{ Current phase } \\
\hline & $\begin{array}{l}\text { Molecule } \\
\text { selection/design } \\
\text { production }\end{array}$ & $\begin{array}{l}\text { Preclinical modeling- } \\
\text { in vitro/in vivo (cell } \\
\text { lines, xenografts) }\end{array}$ & Clinical trials & FDA approved \\
\hline ER & RNF31 inhibitors & $\begin{array}{l}\text { GSK-3 inhibitors (9-ING- } \\
41,9-I N G-87)\end{array}$ & & \\
\hline BRCA1 & & & $\begin{array}{l}\text { PARP inhibitors } \\
\text { (Olaparib, Veliparib, } \\
\text { Talazoparib) }\end{array}$ & \\
\hline \multirow[t]{2}{*}{ ErbB2/HER2/neu } & & Quercetin & $\begin{array}{l}\text { Tyrosine kinase } \\
\text { inhibitors (Afatinib) }\end{array}$ & $\begin{array}{l}\text { Tyrosine kinase inhibitors } \\
\text { (Lapatinib, Neratinib) }\end{array}$ \\
\hline & & & & $\begin{array}{l}\text { Monoclonal antibodies } \\
\text { (Trastuzumab, Ado- } \\
\text { trastuzumabemtansine, } \\
\text { Pertuzumab) }\end{array}$ \\
\hline TRAIL receptors & & $\begin{array}{l}\text { rhTRAIL (co-treatment } \\
\text { of Quercetin) }\end{array}$ & & \\
\hline NEDD4 & $\begin{array}{l}\text { NEDD4 } \\
\text { inhibitors } \\
(\text { beta-TRCP) }\end{array}$ & & & \\
\hline DUBs & DUB3 inhibitors & $\begin{array}{l}\text { USP inhibitors (WP1130, } \\
b-A P 15)\end{array}$ & & \\
\hline Antiestrogens & & & & $\begin{array}{l}\text { Tamoxifen, Raloxifene, } \\
\text { Fulvestrant, Letrozole }\end{array}$ \\
\hline
\end{tabular}

Table 1. Drugs/therapeutic agents for breast cancer related to ubiquitin system.

\section{Abbreviations}

CKIs

Cdk kinase inhibitors

DNA Deoxyribonucleic acid

DUBs Deubiquitinating enzymes

FDA Food and drug administration

HR Homologous recombination

Hsp90 Heat shock protein 90

MDM2 Murine double minute 2 homolog/oncoprotein

NEDD4 Neuronally expressed developmentally downregulated 4

NHEJ Non-homologous recombination 


$\begin{array}{ll}\text { PCNA } & \text { Polymerase DNA } \\ \text { PTM } & \text { Post-translational modifications } \\ \text { RING } & \text { Really interesting new gene } \\ \text { RNF31 } & \text { RING finger protein } 31 \\ \text { RTK } & \text { Tyrosine kinase receptor } \\ \text { SCF } & \text { SKP1-Cullin 1-F-box } \\ \text { SKP1 } & \text { S-phase kinase-associated protein 1 } \\ \text { Ub } & \text { Ubiquitin } \\ \text { UPP } & \text { Ubiquitin proteasome pathway } \\ \text { UPS } & \text { Ubiquitin/proteasome system } \\ \text { HR+ } & \text { Hormone receptor-positive } \\ \text { H2Bub1 } & \text { Monoubiquinated histone H2B } \\ \text { USP44 } & \text { Ubiquitin-specific protease 44 } \\ \text { TNBC } & \text { Triple negative breast cancer } \\ \text { CSC } & \text { Cancer stem cells } \\ \text { ATP } & \text { Adenosine triphosphate } \\ \text { ER } & \text { Estrogen receptor } \\ \text { PR } & \text { Progesterone receptor } \\ \text { HER2 } & \end{array}$

\section{Author details}

Despoina Mourtzoukou ${ }^{1 *}$, Ioannis Drikos ${ }^{2}$, Nikolaos Goutas ${ }^{3}$ and Dimitris Vlachodimitropoulos ${ }^{3}$

*Address all correspondence to: dvlacho@med.uoa.gr

1 Istomedica, Private Anatomic Pathology Lab, Athens, Greece

2 Thriasio General Hospital of Attica, Greece

3 Medical School, National and Kapodistrian University of Athens, Greece 


\section{References}

[1] Breast Cancer: Prevention and Control, Breast Cancer Burden. World Health Organiation (WHO)

[2] Alteri R, Bertaut T, Brinton LA, Fedewa S, Freedman RA, Gansler T, Gaudet MM, Kramer J, Lin CC, McCullough M, MillerK, Newman LA, NiemeyerD, Piercy A, Richards C, SuerAG, Simpson S, Smith R, Wagner D , Xu J. Breast Cancer Facts \& Figures 2015-2016 is a publication of the American Cancer Society, Atlanta, Georgia

[3] U.S. Breast Cancer Statistics, breastcancer.org, March 2017

[4] Pathologyoutlines.com, October 2016

[5] Gallo LH, Ko J, Donoghue DJ. The importance of regulatory ubiquitination in cancer and metastasis. Cell Cycle. 2017 Apr 3;16(7):634-648. DOI: 10.1080/15384101.2017.1288326. Epub 2017 Feb 6. PubMed PMID: 28166483; PubMed Central PMCID: PMC5397262

[6] Rasool M, Malik A, Naseer MI, Manan A, Ansari S, Begum I, Qazi MH, Pushparaj P, Abuzenadah AM, Al-Qahtani MH, Kamal MA, Gan S. The role of epigenetics in personalized medicine: Challenges and opportunities. BMC Medical Genomics. 2015;8(Suppl 1): S5. DOI: 10.1186/1755-8794-8-S1-S5. Epub 2015 Jan 15. Review. PubMed PMID: 25951941; PubMed Central PMCID: PMC4315318

[7] Herhaus L, Dikic I. Expanding the ubiquitin code through post-translational modification. EMBO Reports. 2015 Sep;16(9):1071-1083. DOI: 10.15252/embr.201540891. Epub 2015 Aug 12. Review. PubMed PMID: 26268526; PubMed Central PMCID: PMC4576978

[8] Tu Y, Chen C, Pan J, Xu J, Zhou ZG, Wang CY. The ubiquitin proteasome pathway (UPP) in the regulation of cell cycle control and DNA damage repair and its implication in tumorigenesis. International Journal of Clinical and Experimental Pathology. 2012;5(8):726-738. Epub 2012 Oct 1 PubMed PMID: 23071855; PubMed Central PMCID: PMC3466981Review

[9] Akutsu M, Dikic I, Bremm A. Ubiquitin chain diversity at a glance. Journal of Cell Science. 2016 Mar 1;129(5):875-880. DOI: 10.1242/jcs.183954. Epub 2016 Feb 15. Review. PubMed PMID: 26906419

[10] Johnson DE. The ubiquitin-proteasome system: Opportunities for therapeutic intervention in solid tumors. Endocrine-Related Cancer. 2015 Feb;22(1):T1-17. DOI: 10.1530/ERC14-0005. Epub 2014 Mar 21. Review. PubMed PMID: 24659480; PubMed Central PMCID: PMC4170053

[11] Lim KH, Song MH, Baek KH. Decision for cell fate: Deubiquitinating enzymes in cell cycle checkpoint. Cellular and Molecular Life Sciences. 2016 Apr;73(7):1439-1455. DOI: 10.1007/s00018-015-2129-2. Epub 2016 Jan 13. Review. PubMed PMID: 26762302

[12] Pinto-Fernandez A, Kessler BM. DUBbing cancer: Deubiquitylating enzymes involved in epigenetics, DNA damage and the cell cycle as therapeutic targets. Frontiers in Genetics. 2016 Jul 28;7:133. DOI: 10.3389/fgene.2016.00133. eCollection 2016. Review. PubMed PMID: 27516771; PubMed Central PMCID: PMC4963401 
[13] Klein T, Viner RI, Overall CM. Quantitative proteomics and terminomics to elucidate the role of ubiquitination and proteolysis in adaptive immunity. Philosophical Transactions of the Royal Society A: Mathematical, Physical and Engineering Sciences. 2016 Oct 28;374(2079). Pii:20150372. DOI: 10.1098/rsta.2015.0372

[14] Dantuma NP, Bott LC. The ubiquitin-proteasome system in neurodegenerative diseases: precipitating factor, yet part of the solution. Frontiers in Molecular Neuroscience. 2014 Jul 31;7:70. DOI: 10.3389/fnmol.2014.00070.eCollection 2014

[15] Suryadinata R, Roesley SN, Yang G, Sarčević B. Mechanisms of generating polyubiquitin chains of different topology. Cells. 2014 Jul 1;3(3):674-89. DOI: 10.3390/cells3030674. PubMed PMID: 24987835; PubMed Central PMCID: PMC4197637

[16] Schlesinger DH, Goldstein G, Niall HD. The complete amino acid sequence of ubiquitin, an adenylate cyclase stimulating polypeptide probably universal in living cells. Biochemistry. 1975;14:2214-2218

[17] Hershko A, Ciechanover A. The ubiquitin system. Annual Review of Biochemistry. 1998; 67:425-479

[18] Ciechanover A, Finley D, Varshavsky A. Mammalian cell cycle mutant defective in intracellular protein degradation and ubiquitin-protein conjugation. Progress in Clinical and Biological Research. 1985;180:17-31

[19] Ciechanover A, Finley D, Varshavsky A. Ubiquitin dependence of selective protein degradation demonstrated in the mammalian cell cycle mutants. Cell. 1984;37:57-66

[20] Scheffner M, Nuber U, Huibregtse JM. Protein ubiquitination involving an E1-E2-E3 enzyme ubiquitin thioester cascade. Nature. 1995;373:81-83

[21] Haglund K, Dikic I. Ubiquitylation and cell signaling. The EMBO Journal. 2005;24: 3353-3359

[22] Peng J, Schwartz D, Elias JE, Thoreen CC, Cheng D, Marsischky G, et al. A proteomics approach tounder standing protein ubiquitination. Nature Biotechnology. 2003;21:921-926

[23] Komander D, Rape M. The ubiquitin code. Annual Review of Biochemistry. 2012;81:203-229

[24] Chen S, Davies AA, Sagan D, Ulrich HD. The RING fin ger ATPase Rad5 pof Saccharomyces cerevisiae contributes to DNA double- strand break repair in a ubiquitin-independent manner. Nucleic Acids Research. 2005;33:5878-5886

[25] Thrower JS, Hoffman L, Rechsteiner M, Pickart CM. Recognition of the polyubiquitin proteolytic signal. The EMBO Journal. 2000;19:94-102

[26] Voges D, Zwickl P, Baumeister W. The26Sproteasome: A molecular machine designed for controlled proteolysis. Annual Review of Biochemistry. 1999;68:1015-1068

[27] Orlowski RZ, Kuhn DJ. Proteasome inhibitors in cancer therapy: Lessons from the first decade. Clinical Cancer Research. 2008;14:1649-1657

[28] Feng L, Chen J. The E3 ligase RNF8 regulates KU80 removal and NHEJ repair. Nature Structural \& Molecular Biology. 2012;19:201-206 
[29] Li L, Tao Q, Jin H, van Hasselt A, Poon FF, Wang X, et al. The tumor suppressor UCHL1 forms a complex with p53/MDM2/ARF to promote p53 signaling and is frequently silenced in nasopharyngeal carcinoma. Clinical Cancer Research. 2010;16:2949-2958

[30] Biswas M, Voltz K, Smith JC, Langowski J. Role of histone tails instructural stability of the nucleosome. PLoS Computational Biology. 2011;7:e1002279

[31] Zhou W, Zhu P, Wang J, Pascual G, Ohgi KA, Lozach J, et al. Histone H2A monoubiquitination represses transcription by inhibiting RNA polymerase II transcriptional elongation. Molecular Cell. 2008;29:69-80

[32] Pan MR, Peng G, Hung WC, Lin SY. Monoubiquitination of H2AX protein regulates DNA damage response signaling. The Journal of Biological Chemistry. 2011;286:28599-28607

[33] $\mathrm{Wu} \mathrm{H}$, Leng RP. UBE4B, aubiquitin chain assembly factor is required for MDM2mediated p53 polyubiquitination and degradation. Cell Cycle. 2011;10:1912-1915

[34] Kim ST, Lim DS, Canman CE, Kastan MB. Substrate specificities and identification of putative substrates of ATM kinase family members. The Journal of Biological Chemistry. 1999;274:37538-37543

[35] Acs K, Luijsterburg MS, Ackermann L, Salomons FA, Hoppe T, Dan-tuma NP. The AAA-ATPase VCP/p97 promotes 53BP1 recruitment by removing L3MBTL1 from DNA double-strandbreaks. Nature Structural \& Molecular Biology. 2011;18:1345-1350

[36] Dantuma NP, Hoppe T. Growing sphere of influence: Cdc48/p97 orchestrates ubiquitindependent extraction from chromatin. Trends in Cell Biology. 2012;22:483-491

[37] Jiang N, Shen Y, Fei X, Sheng K, Sun P, et al. Valos in containing protein regulates the proteasome - Mediated degradation of DNA-PKcs in glioma cells. Cell Death \& Disease. 2013;4:e647

[38] Chapman JR, Taylor MR, Boulton SJ. Playing the endgame: DNA double-strand break repair pathway choice. Molecular Cell. 2012;47:497-510

[39] Lemmens BB, Tijsterman M. DNA double - Strand break repair in Caenorhabditis elegans. Chromosoma. 2010;120:1-21

[40] Bunting SF, Nussenzweig A. End-joining, translocations and cancer. Nature Reviews. Cancer. 2013;13:443-454

[41] Dahm-Daphi J, Hubbe P, Horvath F, El-Awady RA, Bouffard KE, Pow-ell SN, et al. Nonhomologous end-joining of site-specific but not of radiation-induced DNA doublestrand breaks is reduced in the presence of wild-type p53. Oncogene. 2005;24:1663-1672

[42] Moynahan ME, Jasin M. Mitotic homologous recombination maintains genomic stability and suppresses tumorigenesis. Nature Reviews. Molecular Cell Biology. 2010;11:196-207

[43] Clejan I, Boerckel J, Ahmed S. Developmental modulation of non- homologous end joining in Caenorhabditis Elegans. Genetics. 2006;173:1301-1317 
[44] Yun MH, Hiom K. Understanding the functions of BRCA1 in the DNA-damage response. Biochemical Society Transactions. 2009 Jun;37(Pt 3):597-604. DOI: 10.1042/BST0370597. PubMed PMID: 19442256

[45] Lok GT, Sy SM, Dong SS, Ching YP, Tsao SW, Thomson TM, et al. Differential regulation of RNF8 mediated Lys48 and Lys63-based poly-ubiquitylation. Nucleic Acids Research. 2012;40:196-205

[46] Mailand N, Bekker-Jensen S, Faustrup H, Melander F, Bartek J, Lukas C, et al. RNF8 ubiquitylates histones at DNA double-strand breaks and promotes assembly of repair proteins. Cell. 2007;131:887-900

[47] Doil C, Mailand N, Bekker-Jensen S, Menard P, Larsen DH, Pepperkok R, et al. RNF168 binds and amplifies ubiquitin conjugates on damaged chromosomes to allow accumulation of repair proteins. Cell. 2009;136:435-446

[48] Ramadan K, Meerang M. Degradation - Linked ubiquitin signal and proteasome are integral component so fDNA double strand break repair: New perspectives for anticancer therapy. FEBS Letters. 2011;585:2868-2875

[49] Al-Hakim A, Escribano-Diaz C, Landry MC, O'Donnell L, Panier S, Szilard RK, et al. The ubiquitous role of ubiquitin in the DNA damage response. DNA Repair (Amst). 2010;9:1229-1240

[50] Mallette FA, Mattiroli F, Cui G, Young LC, Hendzel MJ, Mer G, et al. RNF8 and RNF168 dependent degradation of KDM4A/JMJD2. A trig gers 53BP1 recruitment to DNA damage sites. The EMBO Journal. 2012;31:1865-1878

[51] Zhang S, Chea J, Meng X, Zhou Y, Lee EY, Lee MY. PCNA is ubiquitinated by RNF8. Cell Cycle. 2008;7:3399-3404

[52] Hoppe T. Multiubiquitylation by E4 enzymes: 'one size' doesn't fit all. Trends in Biochemical Sciences. April 2005;30(4)

[53] Hoege C, Pfander B, Moldovan GL, Pyrowolakis G, Jentsch S. RAD6 - Dependent DNA repair is linked to modification of PCNA by ubiquitin and SUMO. Nature. 2002; 419:135-141

[54] Daigaku Y, Davies AA, Ulrich HD. Ubiquitin - Dependent DNA damage by pass is separable from genome replication. Nature. 2010;465:951-955

[55] Drikos I, Nounesis G, Vorgias C. Characterization of cancer linked BRCA1-BRCT missense variants and interaction with phosphoptotein targets. Proteins Journal. (Proteins Structure-Function and Bioinformatics Journal). 2009;77(2):464-476

[56] Wu-Baer F, Lagrazon K, Yuan W, Baer R. The BRCA1/BARD1 heterodimer assembles polyubiquitin chains through an unconventional linkage involving lysine residue K6 of ubiquitin. The Journal of Biological Chemistry. 2003;278:34743-34746

[57] Irminger Finger I, Jefford CE. Is there more to BARD1 than BRCA1? Nature Reviews. Cancer. 2006;6:382-391 
[58] Issaeva N, Bozko P, Enge M, Protopopova M, Verhoef LG, Masucci M, et al. Small molecule RITA binds to p53, blocks p53 - HDM - 2inter - Action and activates p53 function in tumors. Nature Medicine. 2004;10:1321-1328

[59] Surget S, Descamps G, Brosseau C, Normant V, Maiga S, Gomez-Bougie P, et al. RITA (reactivating p53 and inducing tumor apoptosis) is efficient against TP53 abnormal myeloma cells independently of the p53 pathway. BMC Cancer. 2014;14:437

[60] Krajewski M, Ozdowy P, D'Silva L, Rothweiler U, Holak TA. NMR indicates that the small molecule RITA does not block p53 - MDM2 binding in vitro. Nature Medicine. 2005;11:1135-1136

[61] Shangary S, Qin D, McEachern D, Liu M, Miller RS, Qiu S, et al. Temporal activation of p53 by a specific MDM2 inhibitor is selectively toxic to tumors and leads to complete tumor growth inhibition. Proceedings of the National Academy of Sciences of the United States of America. 2008;105:3933-3938

[62] Levine JS, Koh JS, Triaca V, Lieberthal W. Lysophosphatidic acid: A novel growth and survival factor for renal proximal tubular cells. The American Journal of Physiology. 1997; 273:F575-F585

[63] Brinkmann K, Kashkar H. Targeting the mitochondrial apoptotic pathway: A preferred approach in hematology malignancies? Cell Death \& Disease. 2014;5:e1098

[64] Fujita T, Ikeda H, Kawasaki K, Taira N, Ogasawara Y, Nakagawara A, Doihara H.Clinicopathological relevance of UbcH10 in breast cancer. Cancer Science. 2009;100:238-248

[65] van Ree JH, Jeganathan KB, Malureanu L, van Deursen JM. Overexpression of the E2 ubiquitin-conjugating enzyme UbcH10 causes chromosome missegregation and tumor formation. The Journal of Cell Biology. 2010;188:83-100

[66] Narayan G, Bourdon V, Chaganti S, Arias-Pulido H, Nandula SV, Rao PH, Gissmann L, Durst M, Schneider A, Pothuri B, et al. Gene dosage alterations revealed by cDNA microarray analysis in cervical cancer: Identification of candidate amplified and overexpressed genes. Genes, Chromosomes \& Cancer. 2007;46:373-384

[67] Tzelepi V, Zhang J, JF L, Kleb B, Wu G, Wan X, Hoang A, Efstathiou E, Sircar K, Navone $\mathrm{NM}$, et al. Modeling a lethal prostate cancer variant with small-cell carcinoma features. Clinical Cancer Research. 2012;18:666-677

[68] Deshaies RJ, Joazeiro CA. RING domain E3 ubiquitin ligases. Annual Review of Biochemistry. 2009;78:399-434

[69] Berndsen CE, Wolberger C. New insights into ubiquitin E3 ligase mechanism. Nature Structural \& Molecular Biology. 2014;21:301-307

[70] Kajiro M, Hirota R, Nakajima Y, Kawanowa K, So-ma K, Ito I, Yamaguchi Y, Ohie SH, Kobayashi Y, Seino Y, et al. The ubiquitin ligase CHIP acts as an upstream regulator of oncogenic pathways. Nature Cell Biology. 2009;11:312-319 
[71] Jang KW, Lee KH, Kim SH, Jin T, Choi EY, Jeon HJ, Kim E, Han YS, Chung JH. Ubiquitin ligase CHIP induces TRAF2 proteasomal degradation and NF-kappaB inactivation to regulate breast cancer cell invasion. Journal of Cellular Biochemistry. 2011;112:3612-3620; PMID:21793045

[72] Eirew P, Steif A, Khattra J, Ha G, Yap D, Farahani H, Gelmon K, Chia S, Mar C, Wan A, et al. Dynamics of genomic clones in breast cancer patient xenografts at single-cell resolution. Nature. 2015;518:422-426

[73] Witkiewicz AK, McMillan EA, Balaji U, Baek G, Lin WC, Mansour J, Mollaee M, Wagner KU, Koduru P, Yopp A, et al. Whole-exome sequencing of pancreatic cancer defines genetic diversity and therapeutic targets. Nature Communications. 2015;6:674

[74] Beltran H, Prandi D, Mosquera JM, Benelli M, Puca L, Cyrta J, Marotz C, Giannopoulou E, Chakravarthi BV, Varambally S, et al. Divergent clonal evolution of castration-resistant neuroendocrine prostate cancer. Nature Medicine. 2016;22:298-305

[75] ZK Y, Gervais JL, Zhang H. Human CUL-1 associates with the SKP1/SKP2 complex and regulates p21CIP1/WAF1 and cyclin D proteins. Proceedings of the National Academy of Sciences of the United States of America. 1998;95:11324-11329

[76] Carrano AC, Eytan E, Hershko A, Pagano M. SKP2 is required for ubiquitin-mediated degradation of the CDK inhibitor p27. Nature Cell Biology. 1999;1:193-199

[77] Burger AM, Gao Y, Amemiya Y, Kahn HJ, Kitching R, Yang Y, Sun P, Narod SA, Hanna WM, Seth AK. A novel RING-type ubiquitin ligase breast cancer-associated gene 2 correlates with outcome in invasive breast cancer. Cancer Research. 2005;65:10401-10412

[78] Kona FR, Stark K, Bisoski L, Buac D, Cui Q, Dou QP. Transcriptional activation of breast cancer-associated gene 2 by estrogen receptor. Breast Cancer Research and Treatment. 2012;135:495-503

[79] MiyakawaK,RyoA,MurakamiT,OhbaK, YamaokaS, FukudaM, GuatelliJ, YamamotoN. BCA2/Rabring7 promotes tetherin-dependent HIV-1 restriction. PLoS Pathogens. 2009;5:e1000700

[80] Bacopulos S, Amemiya Y, Yang W, Zubovits J, Burger A, Yaffe M, Seth AK. Effects of partner proteins on BCA2 RING ligase activity. BMC Cancer. 2012;12:63

[81] Abbas T, Sivaprasad U, Terai K, Amador V, Pagano M, Dutta A. PCNA-dependent regulation of p21 ubiquitylation and degradation via the CRL4Cdt2 ubiquitin ligase complex. Genes \& Development. 2008;22:2496-2506

[82] Burger A, Amemiya Y, Kitching R, Seth AK. Novel RING E3 ubiquitin ligases in breast cancer. Neoplasia. 2006;8:689-695

[83] Zhi X, Zhao D, Wang Z, Zhou Z, Wang C, Chen W, Liu R, Chen C. E3 ubiquitin ligase RNF126 promotes cancer cell proliferation by targeting the tumor suppressor p21 for ubiquitin-mediated degradation. Cancer Research. 2013;73:385-394 
[84] Nakayama KI, Nakayama K. Ubiquitin ligases: Cell-cycle control and cancer. Nature Reviews. Cancer. 2006;6:369-381

[85] Wang Y, Ren F, Wang Y, Feng Y, Wang D, Jia B, Qiu Y, Wang S, Yu J, Sung JJ, et al. CHIP/ Stub1 functions as a tumor suppressor and represses NF-kappaB-mediated signaling in colorectal cancer. Carcinogenesis. 2014;35:983-991

[86] Wang T, Yang J, Xu J, Li J, Cao Z, Zhou L, You L, Shu H, Lu Z, Li H, et al. CHIP is a novel tumor suppressor in pancreatic cancer through targeting EGFR. Oncotarget. 2014;5:1969-1986

[87] Deryugina EI, Quigley JP. Matrix metalloproteinases and tumor metastasis. Cancer Metastasis Reviews. 2006;25:9-34

[88] Wu Z, Shen S, Zhang Z, Zhang W, Xiao W. Ubiquitin-conjugating enzyme complex Uev1A-Ubc13 promotes breast cancer metastasis through nuclear factor-small ka, CyrillicB mediated matrix metalloproteinase- 1 gene regulation. Breast Cancer Research. 2014;16:R75

[89] Morrison BJ, Morris JC, Steel JC. Lung cancer-initiating cells: A novel target for cancer therapy. Targeted Oncology. 2013;8:159-172

[90] Brooks CL, Gu W. p53 ubiquitination: Mdm2 and beyond. Molecular Cell. 2006 Feb 3;21(3):307-315 Review. PubMed PMID: 16455486; PubMed Central PMCID: PMC3737769

[91] Duffy MJ, Synnott NC, McGowan PM, Crown J, O'Connor D, Gallagher WM. p53 as a target for the treatment of cancer. Cancer Treatment Reviews. 2014 Dec;40(10):11531160. DOI: 10.1016/j.ctrv.2014.10.004 Review. PubMed PMID: 25455730

[92] Gasco M, Shami S, Crook T. The p53 pathway in breast cancer. Breast Cancer Research. 2002;4:70. DOI: 10.1186/bcr426, BioMed Central Ltd 2002

[93] Bertheau P, Lehmann-Che J, Varna M, Dumay A, Poirot B, Porcher R, Turpin E, Plassa LF, de Roquancourt A, Bourstyn E, de Cremoux P, Janin A, Giacchetti S, Espié M, de Thé H, et al. Breast. 2013 Aug;22(Suppl 2):S27-S29. DOI: 10.1016/j.breast.2013.07.005. Review. PubMed PMID: 24074787

[94] Muller PA, Vousden KH. Mutant p53 in cancer: New functions and therapeutic opportunities. Cancer Cell, Volucella. 2014 Mar;25(3):304-317

[95] Parrales A, Iwakuma T. Targeting oncogenic mutant p53 for cancer therapy. Frontiers in Oncology. 2015;5:288. Published online 2015 Dec 21. doi: 10.3389/fonc.2015.00288 PMCID: PMC4685147

[96] Wang Z, Sun Y. Targeting p53 for novel anticancer therapy. Translational Oncology. 2010 Feb;3(1):1-12. PubMed PMID: 20165689; PubMed Central PMCID: PMC2822448

[97] Mahanta S, Pilla S, Paul S. Design of novel Geldanamycin analogue hsp90 alpha-inhibitor in silico for breast cancer therapy. Medical Hypotheses. 2013 Sep;81(3):463-469. DOI: 10.1016/j.mehy.2013.06.012. Epub 2013 Jul 13. PubMed PMID: 23860250 
[98] Prabhu S, Ananthanarayanan P, Aziz SK, Rai S, Mutalik S, Sadashiva SR. Enhanced effect of geldanamycin nanocomposite against breast cancer cells growing in vitro and as xenograft with vanquished normal cell toxicity. Toxicology and Applied Pharmacology. 2017 Apr 1;320:60-72. DOI: 10.1016/j.taap.2017.02.012. Epub 2017 Feb 16. PubMed PMID: 28213093

[99] Jhaveri K, Modi S. Ganetespib: Research and clinical development. OncoTargets and Therapy. 2015 Jul 24;8:1849-1858. DOI: 10.2147/OTT.S65804. eCollection 2015. Review. PubMed PMID: 26244021; PubMed Central PMCID: PMC4521669

[100] Truong T-G, Munster P. Histone deacetylase inhibitors for the treatment of breast cancer: Recent trial data. The Clinical Investigator. 2013;3(6):557-569

[101] Mottamal M, Zheng S, Huang TL, Wang G. Histone deacetylase inhibitors in clinical studies as templates for new anticancer agents. Molecules. 2015 Mar 2;20(3):3898-3941. DOI: $10.3390 /$ molecules20033898

[102] Liu J, Xia H, Kim M, Xu L, Li Y, Zhang L, Cai Y, Norberg HV, Zhang T, Furuya T, Jin M, Zhu Z, Wang H, Yu J, Li Y, Hao Y, Choi A, Ke H, Ma D, Yuan J. Beclin1 controls the levels of p53 by regulating the deubiquitination activity of USP10 and USP13. Cell. 2011 Sep 30;147(1):223-234. DOI: 10.1016/j.cell.2011.08.037. PubMed PMID: 21962518; PubMed Central PMCID: PMC3441147

[103] Jung YY, Lee YK, Koo JS. The potential of Beclin 1 as a therapeutic target for the treatment of breast cancer. Expert Opinion on Therapeutic Targets. 2016;20(2):167-178. DOI: 10.1517/14728222.2016.1085971. Epub 2015 Sep 11. Review. PubMed PMID: 26357854

[104] Sriraman A, Li Y, Dobbelstein M. Fortifying p53 - beyond Mdm2 inhibitors. Aging (Albany NY). 2016 Sep 29;8(9):1836-1837. DOI: 10.18632/aging.101073. PubMed PMID: 27688014; PubMed Central PMCID: PMC5076439

[105] Burgess A, Chia KM, Haupt S, Thomas D, Haupt Y, Lim E. Clinical overview of MDM2/X-targeted therapies. Frontiers in Oncology. 2016 Jan 27;6:7. DOI: 10.3389/ fonc.2016.00007. eCollection 2016. Review. PubMed PMID: 26858935; PubMed Central PMCID: PMC4728205

[106] Tosoni D, Pambianco S, Ekalle Soppo B, Zecchini S, Bertalot G, Pruneri G, Viale G, Di Fiore PP, Pece S. Pre-clinical validation of a selective anti-cancer stem cell therapy for Numbdeficient human breast cancers. EMBO Molecular Medicine. 2017 Mar 15. pii: e201606940. DOI: 10.15252/emmm.201606940. [Epub ahead of print] PubMed PMID: 28298340

[107] Zhu J, Zhao C, Zhuang T, Jonsson P, Sinha I, Williams C, Strömblad S, Dahlman-Wright K. RING finger protein 31 promotes p53 degradation in breast cancer cells. Oncogene. 2016 Apr 14;35(15):1955-1964. DOI: 10.1038/onc.2015.260 Epub 2015 Jul 6. PubMed PMID: 26148235; PubMed Central PMCID: PMC4833873

[108] Zhu J, Zhuang T, Yang H, Li X, Liu H, Wang H. Atypical ubiquitin ligase RNF31: The nuclear factor modulator in breast cancer progression. BMC Cancer. 2016 Jul 26;16:538. DOI: 10.1186/ s12885-016-2575-8. PubMed PMID: 27460922; PubMed Central PMCID: PMC4962416 
[109] Finn RS, Aleshin A, Slamon DJ. Targeting the cyclin-dependent kinases (CDK) 4/6 in estrogen receptor-positive breast cancers. Breast Cancer Research. 2016 Feb 9;18(1):17. DOI: 10.1186/s13058-015-0661-5. Review. PubMed PMID: 26857361; PubMed Central PMCID: PMC4746893

[110] Vidula N, Rugo HS. Cyclin-dependent kinase 4/6 inhibitors for the treatment of breast cancer: A review of preclinical and clinical data. Clinical Breast Cancer. 2016 Feb;16(1):817. DOI: 10.1016/j.clbc.2015.07.005. Epub 2015 Jul 26. Review. PubMed PMID: 26303211

[111] FDA Approved drugs in Oncology/Centerwatch

[112] Wang Z, Fukushima H, Inuzuka H, Wan L, Liu P, Gao D, Sarkar FH, Wei W. Skp2 is a promising therapeutic target in breast cancer. Frontiers in Oncology. 2012 Jan 4;1(57). pii: 18702. PubMed PMID: 22279619; PubMed Central PMCID: PMC3263529

[113] Sun YJ, Wang XK, Li BJ. S-phase kinase-associated protein 2 expression interference inhibits breast cancer cell proliferation. Genetics and Molecular Research. 2015 Aug 10;14(3):9244-9252. DOI: 10.4238/2015.August.10.4. PubMed PMID: 26345857

[114] Cole AJ, Clifton-Bligh R, Marsh DJ. Histone H2B monoubiquitination: Roles to play in human malignancy. Endocrine-Related Cancer. 2015 Feb;22(1):T19-T33. DOI: 10.1530/ ERC-14-0185. Epub 2014 Jun 2. Review. PubMed PMID: 24891457

[115] Lan X, Atanassov BS, Li W, Zhang Y, Florens L, Mohan RD, Galardy PJ, Washburn MP, Workman JL, Dent SY. USP44 is an integral component of N-CoR that contributes to gene repression by deubiquitinating histone H2B. Cell Reports. 2016 Nov22;17(9):23822393. DOI: 10.1016/j.celrep.2016.10.076. PubMed PMID: 27880911; PubMed Central PMCID: PMC5131803

[116] Wilson Xu C, Urasaki Y. Modulation of histone H2B monoubiquitination and treatment of. Cancer. Oct 2013

[117] Gajulapalli VN, Malisetty VL, Chitta SK, Manavathi B. Oestrogen receptor negativity in breast cancer: a cause or consequence? Bioscience Reports. 2016 Dec 23;36(6):e00432. DOI: 10.1042/BSR20160228. Print 2016 Dec. Review. PubMed PMID: 27884978; PubMed Central PMCID: PMC5180249

[118] Zhou Z, Qiao JX, Shetty A, Wu G, Huang Y, Davidson NE, Wan Y. Regulation of estrogen receptor signaling in breast carcinogenesis and breast cancer therapy. Cellular and Molecular Life Sciences. 2014 Apr;71(8):1549. DOI: 10.1007/s00018-013-1376-3. Retraction in: Cellular and Molecular Life Sciences. 2014 Apr;71(8):1549. PubMed PMID: 25031550; PubMed Central PMCID: PMC3962223

[119] McCubrey JA, Steelman LS, Bertrand FE, Davis NM, Sokolosky M, Abrams SL, Montalto G, D'Assoro AB, Libra M, Nicoletti F, Maestro R, Basecke J, Rakus D, Gizak A, Demidenko ZN, Cocco L, Martelli AM, Cervello M. GSK-3 as potential target for therapeutic intervention in cancer. Oncotarget. 2014 May 30;5(10):2881-2911 Review. PubMed PMID: 24931005; PubMed Central PMCID: PMC4102778

[120] Ugolkov et al. GSK3 inhibition overcomes chemoresistance in human breast cancer. Cancer Letters. 2016 Oct 1;380(2):384-392. DOI: 10.1016/j.canlet.2016.07.006.Epub 2016 Jul 14 
[121] Wu W, Koike A, Takeshita T, Ohta T. The ubiquitin E3 ligase activity of BRCA1 and its biological functions. Cell Division. 2008 Jan 7;3:1. DOI: 10.1186/1747-1028-3-1

[122] Livraghi L, Garber JE. PARP inhibitors in the management of breast cancer: Current data and future prospects. BMC Medicine. 2015 Aug 13;13:188. DOI: 10.1186/s12916015-0425-1. Review. PubMed PMID: 26268938; PubMed Central PMCID: PMC4535298

[123] Chustecka Z. Olaparib Positive Results in BRCA Metastatic Breast Cancer. Medscape; February 172017

[124] Kroese M, Zimmern RL, Pinder SE. HER2 status in breast cancer-an example of pharmacogenetic testing. Journal of the Royal Society of Medicine. 2007;100(7):326-329

[125] Vu T, Claret FX. Trastuzumab: Updated mechanisms of action and resistance in breast cancer. Frontiers in Oncology. 2012 Jun 18;2:62. DOI: 10.3389/fonc.2012.00062. eCollection 2012. PubMed PMID: 22720269; PubMed Central PMCID: PMC3376449

[126] Maher M. Current and emerging treatment regimens for HER2-positive breast cancer. Pharmacy and Therapeutics. 2014;39(3):206-212

[127] Jeong JH, An JY, Kwon YT, Li LY, Lee YJ. Quercetin-induced ubiquitination and downregulation of her-2/neu. Journal of Cellular Biochemistry. 2008 Oct 1;105(2):585-595. DOI: 10.1002/jcb.21859. PubMed PMID: 18655187; PubMed Central PMCID: PMC2575035

[128] Zhang X, Munster PN. New protein kinase inhibitors in breast cancer: Afatinib and neratinib. Expert Opinion on Pharmacotherapy. 2014 Jun;15(9):1277-1288. DOI: 10.1517/ 14656566.2014.913570. Epub 2014 Apr 30

[129] Rafaat A, Abd-Rabou A, Reda A. TRAIL combinations: The new 'trail' for cancer therapy (review). Oncology Letters. 2014 May;7(5):1327-1332. Epub 2014 Feb 27

[130] Manouchehri JM, Kalafatis M, Lindner D. Evaluation of the efficacy of TRAIL plus quercetin as a potential breast carcinoma therapeutic. Cancer Research. DOI: 10.1158/15387445.AM2016-1295. Published July 2016

[131] Nourashrafeddin S, Aarabi M, Modarressi MH, Rahmati M, Nouri M. The evaluation of WBP2NL-related genes expression in breast cancer. Pathology Oncology Research. 2015Apr;21(2):293-300. DOI: 10.1007/s12253-014-9820-8. Epub 2014 Nov 25. PubMed PMID:25417742

[132] Chen Y, van de Vijver MJ, Hibshoosh H, Parsons R, Saal LH. PTEN and NEDD4 in human breast carcinoma. Pathology Oncology Research. 2016 Jan;22(1):41-47. DOI: 10.1007/s12253-015-9971-2. Epub 2015 Aug 15. PubMed PMID: 26276352; PubMed Central PMCID: PMC4681749

[133] Ye X, Wang L, Shang B, Wang Z, Wei W. NEDD4: A promising target for cancer therapy. Current Cancer Drug Targets. 2014;14(6):549-556 Review. PubMed PMID:25088038; PubMed Central PMCID: PMC4302323

[134] Pal A, Donato NJ. Ubiquitin-specific proteases as therapeutic targets for the treatment of breast cancer. Breast Cancer Research. 2014;16(5):461 Review. PubMed PMID: 25606592; PubMed Central PMCID: PMC4384352 
[135] Wu Y, Wang Y, Lin Y, Liu Y, Wang Y, Jia J, Singh P, Chi YI, Wang C, Dong C, Li W, Tao M, Napier D, Shi Q, Deng J, Mark Evers B, Zhou BP. Dub3 inhibition suppresses breast cancer invasion and metastasis by promoting Snail1 degradation. Nature Communications. 2017 Feb 15;8:14228. DOI: 10.1038/ncomms14228. PubMed PMID: 28198361; PubMed Central PMCID: PMC5316870

[136] Huang X, Dixit VM. Drugging the undruggables: Exploring the ubiquitin system for drug development. Cell Research. 2016 Apr;26(4):484-498. DOI: 10.1038/cr.2016.31. Epub 2016 Mar 22. Review. PubMed PMID: 27002218; PubMed Central PMCID: PMC4822129

[137] Traboulsi T, Ezzy M, Gleason J. Antiestrogens: structure-activity relationships and use in breast cancer treatment. Journal of Molecular Endocrinology. 2016 Dec;58(1):R15-R31. DOI: 10.1530/JME-16-0024. Epub 2016 Dec 3

[138] Yan SC, Liu YP, Zhang LY, Qu JL, Xu L, Liu J, Zhang Y, Hou KZ, Teng YE, Qu XJ. Ubiquitin ligase c-Cbl is involved in tamoxifen-induced apoptosis of MCF-7 cells by downregulating the survival signals. Acta Oncology. 2011 Jun;50(5):693-699. DOI: 10.3109/0284186X.2010.543144. Epub 2010 Dec 22

[139] Rawat A, Gopal G, Selvaluxmy G, Rajkumar T. Inhibition of ubiquitin conjugating enzyme UBE2C reduces proliferation and sensitizes breast cancer cells to radiation, doxorubicin, tamoxifen and letrozole. Celluar Oncology. 2013 Dec;36(6):459-467. DOI: 10.1007/s13402-013-0150-8. Epud 2013 Sep 27 